\title{
Formação de professores atuantes como educadores ambientais: reflexões mediante a vertente crítica
}

\author{
Marily da Silva Brito* $\bullet$ \\ Instituto Federal de Educação, Ciência e Tecnologia do Ceará, Fortaleza, CE, Brasil \\ Raphael Alves Feitosa** \\ Universidade Federal do Ceará, Fortaleza, CE, Brasil
}

\begin{abstract}
Resumo
A educação ambiental numa perspectiva socioambiental exige a superação de alguns entraves, dentre eles a formação. O presente artigo traz algumas reflexões sobre a formação de professores atuantes como educadores ambientais mediante a abordagem crítica, a partir de síntese teórica elencada por meio de pesquisa bibliográfica. Para tanto, introduzimos a temática abordando o cenário da EA na atualidade e identidade docente. Em seguida tratamos do educador ambiental frente ao processo de formação e de reflexões sobre estratégias formativas. Por fim, nos posicionamos reafirmando a necessária formação e que ação educativa-ambiental propõe uma mudança em diversos aspectos da prática pedagógica, envolvendo ação individual e coletiva, oriundas da formação inicial e continuada.
\end{abstract}

Palavras-chave: Educador ambiental; Formação; Educação Ambiental crítica.

\begin{abstract}
Training of teachers acting as environmental educators: reflections on the critical aspect

When we look at environmental education from a socio-environmental perspective it requires overcoming some obstacles, among which training. The present article aims to bring some reflections on the formation of active teachers as environmental educators through a critical approach, based on a theoretical synthesis based on bibliographical research. In order to do so, we introduce the theme addressing the current Environmental Education scenario, teaching identity. Next we address the environmental educator before the formation process and reflections on training strategies. Finally, we position ourselves reaffirming the necessary formation and what action educational-environmental proposes a change in several aspects of pedagogical practice, involving individual and collective action, arising from initial and continuing training. Keywords: Environmental Educator; Formation; Environmental Education Critic
\end{abstract}

\section{Resumen}

Formación de profesores actuadores como educadores ambientales: reflexiones frente a vertiente crítica

La educación ambiental en una perspectiva socioambiental exige la superación de algunos obstáculos, entre ellos la formación. El presente artículo pretende

\footnotetext{
*E-mail: marilysilvabrito@gmail.com

${ }^{* *}$ E-mail: raphael.feitosa@ufc.br
} 
traer algunas reflexiones sobre la formación de profesores actuantes como educadores ambientales mediante el abordaje crítico, a partir de síntesis teórica que se elabora por medio de investigación bibliográfica. Para ello, introducimos la temática abordando el escenario de la EA en la actualidad, identidad docente. En seguida tratamos al educador ambiental frente al proceso de formación e reflexiones sobre estrategias formativas. Por fim, nos posicionamos reafirmando a necessária formação e que ação educativa-ambiental propõe uma mudança em diversos aspectos da prática pedagógica, envolvendo ação individual e coletiva, oriundas da formação inicial e continuada.

Palabras clave: Educador ambiental; Entrenamiento; Educación ambiental crítica.

\section{Introdução}

A realidade das relações sociedade-natureza ocasiona muitos desafios para a prática do professor, exigindo uma nova (ou reflexão sobre) postura e concepções mediante o desafio enquanto educador. Esse desafio acontece, pois, à medida que as demandas sociais ficam mais complexas, apresentam-se novos desafios epistemológicos para responder às problemáticas, nas quais vemos a formação inicial e continuada como aliadas para o sucesso das práticas curriculares.

Isso, pois, ao referir-se às questões ambientais e ao debate social incorporado no contex to educativo-escolar, pressupõe-se: “[...] um debate plural e por vezes, tenso, tanto no que se refere à compreensão sobre a natureza e complexidade do tema, como também em relação a suas implicações de caráter político e ideológico” (CAMPOS, 2015, p. 267).

Este caráter citado, corresponde a uma vertente crítica da Educação Ambiental (EA) a qual propõe “[...] uma definição de novos paradigmas educativos centrados na preocupação por iluminar a realidade, e isto supõe a formulação de novos objetos de referência conceitual, principalmente a transformação de conceitos e práticas sociais" (LOUREIRO, 2006, p. 7) que vem em contraposição à EA tradicional (também chamada de conservadora), que pode ser compreendida como a vertente que apresenta características hegemônicas e que possui uma visão mecanicista da ciência, simplificadora dos fenômenos, além de não poder ou não querer revelar as relações de poder que estruturam a sociedade atual (GUIMARÃES, 2004).

Consideramos tal vertente limitada e fragilizada para a realidade que nos cerca, pois a tendência conservadora de acordo com Layrargues e Lima (2011) vem 
com o propósito de apenas despertar uma nova sensibilidade humana para com a natureza, com vínculos afetivos integrados, desenvolvendo-se a lógica do "conhecer para amar, amar para preservar", orientada pela conscientização "ecológica”, com ideário romântico. Foi inspirador do movimento preservacionista, trazendo bem-estar, valorização e proteção do ambiente natural, demonstrando ainda uma relação dicotômica entre ser humano e ambiente.

Partindo de tais pressupostos, compreendemos que a vertente crítica da EA, por sua vez, aglutina as correntes da EA popular, emancipatória, transformadora e no processo de gestão ambiental, apoiando-se na revisão crítica dos fundamentos que proporcionam a dominação do ser humano e dos mecanismos de acumulação do capital, buscando o enfrentamento político das desigualdades e da injustiça socioambiental com uma abordagem pedagógica que problematiza os contextos societários em sua interface com a natureza (LAYRARGUES, LIMA, 2011).

Assim, se há na EA um discurso do novo ou a intencionalidade de buscá-lo, contudo, isso se dá, muitas vezes, sem base teórica ou motivação política para uma efetiva ruptura no nível científico e da sociedade, caindo numa verdadeira armadilha paradigmática (GUIMARÃES, 2004).

Tal armadilha paradigmática pregada por Guimarães (2006) no cenário da EA está pautada pelo fato de observarmos que, durante mais de 25 anos no meio educativo formal e informal brasileiro, e até mais tempo em nível mundial, as comunidades escolares desenvolvem atividades em EA (muitas vezes apoiadas por empresas, Organizações Não Governamentais - ONG) e os professores demonstram-se cada vez mais sensíveis à dimensão ambiental, como por exemplo, as famosas atividades de reciclagem ou reutilização de lixo, coleta seletiva, reutilização de materiais dentre tantas. Porém, ocorreram neste mesmo período a maior degradação ambiental e seu aumento gradativo, até mesmo no entorno destas escolas (GUIMARÃES, 2006).

Nessa perspectiva, levantamos o seguinte questionamento: será que a EA não é capaz de contribuir para a construção da sustentabilidade ${ }^{1}$ ambiental?

\footnotetext{
${ }^{1}$ Trazemos este termo no sentido de sustentavelmente justo (os bens naturais estarão ao alcance de todos?; a fome será erradicada a partir da conservação dos solos etc.?; a moradia com saneamento básico estará ao alcance dos menos favorecidos?; o ambiente será igualitário proporcionando dignidade sem distinção? quais as ferramentas para tal?; dentre outros questionamentos).
} 
Seguindo o exposto por Guimarães (2006), compreendemos que mesmo os educadores bem-intencionados apresentam práticas movidas pela modernidade, tendo em vista que são seres sociais e vivenciam tal sociedade moderna e tendem a perpetuá-la (GUIMARÃES, 2006).

Temos, então, “[...] professores reféns da armadilha paradigmática, manifestada por uma visão ingênua da realidade e uma prática conservadora” (GUIMARÃES, 2006, p. 25), tendo essa visão caracterizada por ser reduzida, não percebendo os conflitos e as relações de poder, e simplista por estabelecer relações lineares de causa e efeito, configurando uma EA tradicional. Assim, tendendo a reproduzir práticas educativas consolidadas, como educação comportamentalista - transmitindo conhecimentos (cognitivos) e provocando a sensibilização, o indivíduo pode transformar seu comportamento incorreto e teremos a soma de indivíduos transformados em uma sociedade. Se esta forma fosse eficaz, não estaríamos vivendo uma crise ambiental tão grave, pois a preservação e conservação já está bem difundida e professada no meio social (GUIMARÃES, 2006).

Mediante o exposto, o presente artigo traz reflexões sobre a formação de professores atuantes como educadores ambientais mediante a abordagem crítica em contrapartida à EA tradicional a partir da síntese teórica elencadas por meio de pesquisa bibliográfica.

Este levantamento bibliográfico, aqui realizado, sobre a formação de educadores ambientais, surgiu de uma pesquisa realizada no Programa de Pós-graduação em Ensino de Ciências e Matemática (PGECM) do Instituto Federal de Educação, Ciência e Tecnologia - IFCE/Fortaleza, o qual visa analisar as contribuições de uma prática curricular em EA na tratativa do tópico recursos hídricos e suas implicações para uma abordagem crítica, correlacionados aos percursos formativos e concepções docentes, a não disciplinarização da EA e a proposta curricular.

Buscamos um recorte temporal de pesquisas que estejam compreendidas entre os anos de 1999 até o ano de 2020, período que compreende a EA como política pública nacional (BRASIL, 1999), destacando, neste escrito, autores que tratam do socioambientalismo atrelado à EA crítica, tais como: Guimarães (2006; 2004), Campos (2015), Torales (2013), Loureiro (2006), Feitosa e Figueiredo (2013), Tozoni-Reis (2002) e Layrargues e Lima (2011).

Vemos a relevância de tais reflexões, pois se faz importante a contínua discussão sobre a formação do professor enquanto educador ambiental, uma vez que 
a EA assumiu uma importância crescente nas últimas décadas, sendo incorporada e reconhecida nos textos base das políticas públicas educacionais e nas práticas cotidianas das escolas, constituindo-se em um campo de conhecimentos e ação de caráter híbrido, que deve envolver a relação entre diversas disciplinas e áreas de conhecimento (CAMPOS, 2015).

Partindo de tais pressupostos, a EA deve apropriar-se de caráter crítico, valendo destacar que grande parte das práticas são desenvolvidas e motivadas pela iniciativa dos docentes, havendo a necessária formação inicial e continuada (TORALES, 2013), a qual será discutido na próxima seção.

\section{Professores/educadores ambientais mediante o processo de formação}

Ao iniciarmos, faz-se necessário frisar que o papel de educador ambiental é tido como plural, podendo estar presente em espaços formais (sala de aula no fazer docente e práticas curriculares, abrangendo todas as áreas de estudos, configurando assim, como interdisciplinar) ou espaços não formais atrelados a pesquisadores, movimentos sociais, ONG, dentre outros que possuem interesses pelas questões educativas ambientais, sendo compreendido como: “[ ...] aquele(a) que exerce alguma atividade sistematizada de educação ambiental, bem como aquele(a) cuja profissão lhe possibilita atuar na dimensão educativa presente nas relações culturais, numa perspectiva ambiental” (FEITOSA, FIGUEIREDO, 2013, p. 100).

É importante salientar que o educador ambiental não se reduz apenas a atividades sistematizadas e focadas na questão ambiental, imprimindo tal debate à sua prática cotidiana devido a complexidade dessa problemática, o que vai em consonância com Tozoni-Reis (2002) que corrobora, afirmando que os educadores ambientais possuem função social de síntese, na perspectiva da capacidade de integrar os conhecimentos e a cultura com a formação socioambiental dos sujeitos.

Partindo de tais pressupostos, acastelarmos que a formação de professores para atuarem como educadores ambientais exige especificação, pois há uma distinção entre as características das funções. Entende-se que nem todos os professores são, identificam-se ou possuem características de educadores ambientais, bem como nem todos os educadores ambientais possuem a formação ou os conhecimentos necessários para o exercício da docência (CAMPOS, 2015). 
Damos uma atenção especial para essa formação de professores atuantes como educadores ambientais (que agem e/ou identificam-se como tal), uma vez que não podem estar alheios aos processos educativo-ambientais e seus princípios, principalmente por sua missão e responsabilidade.

Mediante a necessidade e carência de formação específica, os professores/educadores ambientais acabam por não levantarem questionamentos e não problematizarem questões como: as causas profundas da crise ambiental envolvidos nos paradigmas modernos com suas ideologias, a abrangência histórica, que as relações desarmônicas entre natureza-homem são construídas socialmente e que os problemas ambientais manifestam-se em conflito de interesses privados e o bem coletivo.

Nesse contexto, concordamos quando Leroy e Pacheco (2006) trazem o educador ambiental como protagonista nesse processo, afirmando que:

A verdadeira educação ambiental deve ter como preocupação proteger não só as águas, o ar, as florestas, a flora e a fauna, mas, também, os homens e as mulheres que, muitas vezes exatamente por reunirem todas as características que os tornam mais suscetíveis à injustiça ambiental - miséria, pobreza, situação de risco em todos os sentidos, principalmente falta de (in) formação ou ignorância -, tornam-se, ao mesmo tempo, vítimas e algozes de seu entorno (p. 68-69).

É importante frisar que os autores acima indicados ressaltam que não defendem o paternalismo aos sujeitos, considerando que tais condições lhes atribuem o poder de tudo fazer sem serem responsabilizados. Porém defendem que para aqueles “[...] que ao mesmo tempo sofrem e são agentes de sofrimento (para a natureza, para seus semelhantes e para si mesmos), nossa estratégia de ver outra” (LEROY, PACHECO, 2006, p. 69). Reafirmam que para essas pessoas deve ser como nunca educadores, principalmente ao desvelar as ideologias e proporcionar a instrumentalização por meio do saber.

Em uma crítica aos aspectos conservacionistas e tradicionais da EA, Torales (2013) indica que elas ainda vêm se perpetuando. O educador é responsável pela execução e a faz a partir de seus conhecimentos, representações, intencionalidades sobre a educação ambiental e sobre as problemáticas que assolam as questões ambientais. Assim, são colocados diante de exigências, desafios sociais e das problemáticas atuais (dentre elas as questões ambientais), as quais vão agir de acordo com seus pressupostos e formação, ou até mesmo de forma tácita utilizando a intuição ou experiências vividas enquanto aluno ou mesmo enquanto docente. 
Nesse contexto, a ação educativa-ambiental propõe uma mudança em diversos aspectos da prática pedagógica, a qual, segundo Campos (2015), não se constitui como uma tarefa fácil pois implica mudanças curriculares e didáticas, envolvendo ação individual e coletiva, pois:

[...] a educação ambiental constitui-se, desde sua origem, em uma opção de contracultura ao modelo hegemônico de desenvolvimento que desconsidera os danos causados ao meio ambiente pelo modo de produção e consumo, exigindo uma ação política dos educadores, fundamentada nas opções ideológicas de cada um e na capacidade de crítica social (p. 267).

Mediante tal necessidade, faz-se necessário refletir sobre alguns cenários e estratégias formativas (grupos de pesquisa e estudos, cursos de formação de educadores e seus currículos e formação de formadores) através de considerações realizadas por vários pesquisadores da área.

\section{Cenários e estratégias formativas de professores/educadores ambientais}

Este tópico analisará alguns cenários e estratégias formativas de professores/ educadores ambientais através de resultados empíricos e reflexões realizadas por vários pesquisadores da área.

Considera-se que a educação é essencial para possibilitar uma mudança socioambiental, sendo necessário pensar em estratégias formativas para a pluralidade de educadores ambientais (FEITOSA, FIGUEIREDO, 2013), e ainda se acredita que haja espaços e pertinência para a formulação de novas propostas formativas para os(as) educadores(as) ambientais sobre as características dos cenários formativos.

Mediante o exposto, refletiremos estratégias como grupos de pesquisa e estudos, a dimensão ambiental em cursos de formação de educadores, o currículo na promoção da prática da transversalidade em EA e a formação de formadores.

\section{Grupos de pesquisa e estudos}

No âmbito da formação, a participação em grupos de pesquisa sobre EA pode favorecer e potencializar a profissionalização (FEITOSA, FIGUEIREDO, 2013). Isso, pois:

Os grupos de pesquisa/estudo podem ser locais permeados pelos processos de ensino-aprendizagem colaborativo. Isso pode permitir uma ampla gama de possibilidades para a formação inicial e continuada de educadores ambientais, como num movimento artístico crítico-reflexivo que gera cores e formas mandálicas, de colaboração, parceria e aprendizado mútuo (p. 104). 
Nessa perspectiva, os autores supracitados lançam mão de uma pesquisa que vem a contribuir para as discussões aqui presentes, desenvolvida em um grupo de pesquisa da Universidade Federal do Ceará (UFC) chamado de Grupo de Estudos e Pesquisas em Educação Ambiental Dialógica, Perspectiva Eco-Relacional e Educação Popular Freireana (Gead), com o intuito de analisar o que os estudantes pesquisadores compreendem sobre as atividades experienciadas no grupo, bem como investigar as contribuições da referida confraria para a formação de educadores(as) ambientais (FEITOSA, FIGUEIREDO, 2013).

Concluíram que o grupo de pesquisa Gead foi visto pelos seus membros como uma possibilidade de formação humana colaborativa, estimulando a criatividade, a diversidade de pontos de vista e os laços de companheirismo. Colaboram ainda com o ponto de vista da EA os quais apontam:

[...] as ações-reflexões que ocorreram no Gead foram o "florescer de novas perspectivas" para muitos de seus integrantes. Segundo os companheiros do grupo, a diversidade de propostas existentes no grupo permite a aquisição de uma visão mais abrangente sobre o tema, possibilitando avançar com relação às propostas mais conservadoras da educação ambiental (FEITOSA, FIGUEIREDO, 2013, p. 111).

Através de tais resultados, visualiza-se que é possível arquitetar relações entre graduandos, pós-graduandos e professores pesquisadores, abrindo espaço para o desenvolvimento de educadores ambientais que aliem a pesquisa com a práxis transformadora, através de um aprendizado cooperativo entre noviços e profissionais experientes. Torna-se ainda mais relevante, pois, através da formação de confrarias multidisciplinares (que são formadas por partícipes de várias áreas da academia), essa diversidade, segundo os autores, pode proporcionar o desenvolvimento de ações interdisciplinares para a formação de educadores ambientais (FEITOSA, FIGUEIREDO, 2013).

Nesse contexto, quando se lança um olhar sobre formação vinculada à formalidade em universidades, há indicativos, segundo Tozoni-Reis (2002), de que, durante muito tempo, os cursos universitários estavam ligados a uma visão naturalística, com características de busca da conservação e a (re)inserção do ser humano na dinâmica ecológica. Contudo acredita-se que nos últimos anos a universidade vem abrindo espaço para outros paradigmas (TOZONI-REIS, 2002), conforme veremos a seguir.

\section{Dimensão ambiental em cursos de formação de educadores}

Tozoni-Reis (2002), estudando sobre a dimensão ambiental em cursos de formação de educadores da Universidade Estadual Paulista Júlio de Mesquita Filho (Unesp), 
identificou duas tendências conservadoras constantes, tanto em representações quanto em práticas de professores universitários, e as denominou de natural e racional.

A tendência natural traz a compreensão de que as relações ser humano-natureza são definidas pela própria natureza e diferencia-se da tendência racional a qual traz que as relações ser humano-natureza são determinadas pelos conhecimentos científicos. A autora afirma que, para a superação dessas duas tendências, a abordagem histórica é uma alternativa que reflete que tais relações são construídas social e politicamente pelo conjunto dos homens. Esta tendência vem na perspectiva de luta contra a alienação, da exploração do homem pelo homem e da exploração da natureza pelos seres humanos.

Na tentativa de ilustrar ainda mais tal cenário, refletimos sobre um estudo de Teixeira e Torales (2014), que lança um olhar sobre o papel das licenciaturas na formação de futuros professores visando a institucionalização da EA e afirma que:

Diante do avanço da educação ambiental na educação básica, o professor é colocado diante de exigências às quais ele responde com dificuldade e para as quais os cursos de licenciatura pouco contribuem. Certo distanciamento dos professores da educação ambiental tem como justificativa desde condições de trabalho que dificultam inovações e mais esforços, até a constatação de que não estão preparados para trabalhar com a educação ambiental (p. 129).

Nessa análise, os autores supracitados apresentam resultados de uma pesquisa exploratória sobre ações formativas, considerando as características teóricas e epistemológicas do conhecimento e as condições institucionais de seu desenvolvimento na universidade.

Nesse entremeio faz-se importante frisar que a inserção da EA nos currículos de formação de professores vem com exigência Política Nacional de Educação Ambiental (Pnea) a partir da Lei nº 9.795/1999 (BRASIL, 1999), a qual explicita que a dimensão ambiental deve estar presente nos currículos de formação de professores em todos os níveis e disciplinas, e em seu artigo $8^{\circ}$, inciso $3^{\circ}$, que:

$\S 3^{\circ}$ As ações de estudos, pesquisas e experimentações voltar-se-ão para:

I - o desenvolvimento de instrumentos e metodologias, visando à incorporação da dimensão ambiental, de forma interdisciplinar, nos diferentes níveis e modalidades de ensino;

\section{$[\cdots]$}

III - o desenvolvimento de instrumentos e metodologias, visando à participação dos interessados na formulação e execução de pesquisas relacionadas à problemática ambiental;

IV - a busca de alternativas curriculares e metodológicas de capacitação na área ambiental; [...]. 
Nas universidades, a temática surge com o termo "ambientalização de disciplinas”, apontando para disciplinas isoladas (o que não é recomendação dos estudos e políticas públicas em EA) e perdendo seu potencial transversal e interdisciplinar, ao fazer compreender que a temática ambiental se dissipa nas instituições de ensino superior, mas encontra resistência em estabelecer novas relações entre disciplinas, resistência em departamentos e disciplinas que isolam conhecimentos (TEIXEIRA, TORALES, 2014). Baseados em tais estudos, concluíram que, nas ementas e na bibliografia das disciplinas, há a presença do histórico da EA, as políticas públicas, a heterogeneidade e a transformação da racionalidade e do paradigma do conhecimento, tendo a presença do socioambientalismo, contemplando os objetivos da EA crítica e emancipatória (TEIXEIRA, TORALES, 2014). Os autores ressaltam que:

A abordagem exploratória das disciplinas constata a presença da discussão
político-epistemológica em torno da Educação Ambiental, mais afim ao seu
potencial “transformador" indicado anteriormente no bojo dos argumentos
apresentados neste texto. Contudo, o que está nas ementas, nos programas
e bibliografias, não garante esta afinidade, assim como não garante que ela
seja interpretada pelo aluno enquanto tal (TEIXEIRA, TORALES, 2014,
p. 140).

Percebe-se, segundo Teixeira e Torales (2014), que o fazer docente e a formação tratam de fatores subjetivos e objetivos que envolvem diferentes interpretações, atualizações, conduções e apreensões por parte de todos os sujeitos envolvidos, que vem a determinar o resultado final sob influências das disciplinas propostas e que repercutem na ação educativo-ambiental.

Não se pode negar que o contato do licenciando com as disciplinas de formação o introduz nos fundamentos da EA e no caminho potencial transformador que ela carrega. Contudo, cargas horárias limitadas, disciplinas tradicionais (sem seu caráter transversal), professores sem formação ou pesquisas na área podem ser indícios de obstáculos (TEIXEIRA, TORALES, 2014).

\section{Currículo na promoção da prática da transversalidade em Educação Ambiental}

Continuando na tratativa de estratégias de formação de educadores ambientais, Araújo e Santos (2009) em pesquisa realizada na Universidade do Estado do Amazonas em cursos de licenciaturas da Escola Normal Superior, com objetivo de estruturar uma alternativa curricular para promoção da prática da transversalidade, permeada pela EA e voltada para uma epistemologia ambiental, de modo a refletir no ensino básico, afirmam que: 
Muitas são as mudanças e as dificuldades para a prática da Interdisciplinaridade, contudo os Temas Transversais como reflexos dos problemas sociais, econômicos atitudinais, comportamentais, de toda problemática contextual que permeia o ser humano, conseqüentemente, das preocupações das nossas sociedades atuais, tanto ao nível local, como planetário, juntamente com aprendizagens informais desvalorizadas e sofridas de preconceitos, poderiam exercer uma funcionalidade educativa, social e até mesmo psicológica, por se enxergarem como agentes. Representariam perfeitamente essas pontes entre o conhecimento comum e o escolar (ARAÚJO, SANTOS, 2009, p. 7).

Para as autoras, a transversalidade pode ser vista como um caminho para a prática da interdisciplinaridade, promovendo assim um discente crítico, reflexivo, com uma visão ampla e analítica da sociedade, das interações em que ocorrem (ARAÚJO, SANTOS, 2009).

Trouxeram, como sugestão em sua pesquisa, a criação de uma disciplina optativa intitulada “Temas Transversais no Ensino Básico”, para os cursos de Licenciatura em Biologia, Geografia, Letras, Matemática, Pedagogia e Normal Superior, acompanhada de inúmeros obstáculos, pois se faz necessário não apenas uma reforma da Educação, mas antes uma reforma do pensamento (ARAÚJO, SANTOS, 2009).

Visando assim contribuir para um repensar da formação profissional, de modo a "minimizar o conflito entre a vocação verticalizada da ciência e a complexidade horizontalizada da realidade, problematizando a prática da transversalidade, que reflita a complexidade da realidade, assim como os processos educativos" (ARAÚJO, SANTOS, 2009, p. 9), a referida pesquisa e intervenção na formação do professor é vista pelas autoras como potencializadora a projetar mudanças significativas na educação básica. Segundo elas:

Este é um dos desafios que as instituições precisam enfrentar na formação de profissionais comprometidos com a problemática educacional, ambiental contemporânea, fomentando a necessária mudança, partindo do perfil do profissional que o mundo atual espera (ARAÚJO, SANTOS, 2009, p. 9).

Formação de formadores

Não podemos finalizar tais reflexões sem nos depararmos com novos questionamentos que surgem na efervescência das temáticas: "Como formar educadores ambientalmente responsáveis que trabalhem transversal e interdisciplinarmente a temática nas disciplinas, se os formadores são frutos de formação em moldes tradicional?” e "Como esperar que haja mudanças nos discentes apenas por carregarem nos currículos uma disciplina com ementa, bibliografia ou nomenclatura ambiental?". 
Pimenta e Anastasiou (2010) relatam que, quando os professores chegam à docência universitária, trazem inúmeras percepções do que é ser professor, algumas adquiridas enquanto alunos, as quais possibilitam dizer quais eram bons professores, formando modelos positivos e negativos os quais se tornam espelhos, e ainda os que compreendem o que é ser professor por intermédio de experiências de outros, assim como estereótipos da profissão.

Há ainda um certo consenso de que a docência no ensino superior não requer formação no campo do ensinar. Para ela (docência), seria suficiente o domínio de conhecimentos específicos, pois o que a identifica é a pesquisa e/ou o exercício profissional no campo (PIMENTA, ANASTASIOU, 2010, p. 36).

Nesse aspecto percebe-se um equívoco, uma vez que o papel de docente, além de possuir habilidades com os conhecimentos específicos e pesquisas, traz a necessidade de aperfeiçoamento no âmbito do desenvolvimento dos discentes que vão além de conteúdos e sim da humanização, da Didática (no seu sentido amplo), na qualificação profissional (especializações em Docência do Ensino Superior), na criticidade, da cidadania, do seu papel na sociedade.

Mediante tal contexto, há a necessidade de formadores que possam formular sínteses socioambientais, em acordo com as reformulações formais dos currículos dos cursos, havendo a atenção destinada a fundamentação teórica para tal.

Segundo Tavares (2017), há carência de uma fundamentação teórica que permita compreender a EA em sua complexidade, que permita problematizar modos de ser e estar com constante busca de articulação de saberes nas mais diversas áreas de conhecimentos, não podendo deixar de explorar ainda referenciais teóricos, históricos, legislação, parâmetros curriculares e diretrizes da educação ambiental.

Tal autora ressalta ainda uma "insegurança” epistemológica presente e que se evidencia na inserção e articulação nas aulas do ensino superior com produções acadêmicas voltadas às questões ambientais e educativas de zelo ao meio (TAVARES, 2017).

Assim, é preciso uma revisão na prática docente dos professores, quanto à percepção de suas funções na universidade como formadores de cidadãos e de futuros profissionais docentes.

\section{Considerações finais}

Os educadores cada vez estão mais sensíveis à dimensão ambiental (com ações e militâncias próprias sem necessariamente estarem atrelados a políticas públicas), 
porém com transformações pouco significativas uma vez que os problemas ambientais só têm a serem agravados.

Defende-se então uma EA crítica em oposição à tradicional por seu poder hegemônico, reducionista e fragilizado (LOUREIRO, 2006).

Nesse entremeio, as questões ambientais propostas de forma interdisciplinar e transversal são tidas como um desafio a ser superado, em especial quando as mesmas são vistas como algo externo, não diretamente relacionado aos conteúdos programáticos, podendo ainda estarem atreladas ao senso comum ou deixadas de serem abordadas por conta de inúmeros e longos conteúdos elencados no currículo.

Assim, construir debates contemporâneos na formação de professores sobre a interdisciplinaridade na EA passa pela aceitação de que a realidade é ontologicamente múltipla, pela história das ciências, base paradigmática, pelo diálogo transparente e objetivo entre disciplinas, métodos e suas bases epistemológicas (LOUREIRO, 2006).

Conclui-se assim que a ação educativa-ambiental propõe uma mudança em diversos aspectos da prática pedagógica, o qual não se constitui como uma tarefa fácil pois implica mudanças curriculares e didáticas, envolvendo ação individual e coletiva (CAMPOS, 2015) oriundas da formação inicial e continuada.

Acredita-se através dos estudos que haja diversos espaços e pertinência para a formulação de novas propostas formativas para os(as) educadores(as) ambientais.

Considera-se ainda que o contato do licenciando com as disciplinas de formação o introduz nos fundamentos da EA e no caminho potencial transformador que ela carrega, necessitando, nesse âmbito, que as instituições de Ensino superior superem as cargas horárias limitadas, a oferta de disciplinas tradicionais (sem seu caráter transversal), professores sem formação ou pesquisas na área podem ser considerados indícios de obstáculos (TEIXEIRA, TORALES, 2014).

Nesse contexto, a transversalidade na universidade é vista como um caminho para a prática da interdisciplinaridade, promovendo assim um discente crítico, reflexivo, com uma visão ampla e analítica da sociedade, das interações em que ocorrem (ARAÚJO, SANTOS, 2009) na tentativa de minimizar o conflito entre a vocação verticalizada da ciência e a complexidade horizontalizada da realidade.

A abordagem interdisciplinar das questões ambientais vem associar os conhecimentos científicos e não científicos visando a constituição do sujeito integral, por 
meio de um trabalho coletivo que envolve conteúdos, disciplinas e a própria organização da escola, utilizando a contribuição das várias disciplinas (conteúdo e método) para a compreensão e explicação das problemáticas em busca da superação da compartimentação e a fragmentação do saber (COSTA, LOUREIRO, 2013). Nesse sentido:

O professor interdisciplinar percorre as regiões fronteiriças flexíveis onde o "eu" convive com o "outro" sem abrir mão de suas características, possibilitando a interdependência, o compartilhamento, o encontro, o diálogo e as transformações. Esse é o movimento da interdisciplinaridade caracterizada por atitudes ante o conhecimento (TRINDADE, 2008, p. 82).

Portanto, rever os processos formativos (dilemas e necessidades), as estratégias e contextos de formação do professor é tido como potencializador a projetar mudanças significativas na Educação Básica, configurando-se como um dos desafios que as instituições precisam enfrentar na formação de profissionais comprometidos com a problemática educacional, ambiental contemporânea, fomentando a necessária mudança (ARAÚJO, SANTOS, 2009).

Nesse entremeio há a necessidade de formadores que possam formular sínteses socioambientais, em acordo com as reformulações formais dos currículos dos cursos de graduação ou de formação continuada, havendo a atenção destinada a fundamentação teórica para tal.

Finalizamos este texto, mas sem intenções de encerrar as discussões, pois as mesmas envolvem muitos fatores, sujeitos e contextos (tendo em vista que a educação ambiental pode acontecer em diferentes âmbitos mediante seu caráter plural), com o desejo de ter contribuído para a temática e para reflexões sobre os dilemas e necessidades que envolvem o professor atuante como educador ambiental em espaços formais, o qual vivencia os reflexos de sua formação (ou ausência da mesma) em sua prática, com os desafios impostos por sua missão enquanto educador frente ao social e na tratativa de respostas às políticas públicas

\section{Referências}

ARAÚJO, F. M.; SANTOS, E. C. Educação ambiental e a prática da transversalidade na formação de professores: reflexos no ensino básico. In: ENCONTRO NACIONAL DE PESQUISA EM EDUCAÇÃO EM CIÊNCIAS, 7. 2009, Florianópolis. Anais... Florianópolis, SC: Universidade Federal de Santa Catarina, 2009. Disponível em: <http:// posgrad.fae.ufmg.br/posgrad/viienpec/pdfs/686.pdf>. Acesso em: 25 nov. 2018. 
BRASIL. Lei Nº 9.795, de 27 de abril de 1999. Dispõe sobre a educação ambiental, institui a política nacional de educação ambiental e dá outras providências. Diário Oficial da União, 28 abr. 1999.

CAMPOS, M. A. T. A formação de educadores ambientais e o papel do sistema educativo para a construção de sociedades sustentáveis. Revista Eletrônica do Mestrado em Educação Ambiental, Rio Grande, v. 32, n. 2, p. 266-82, jul./dez. 2015. https://doi. org/10.14295/remea.v32i2.5543

COSTA, C. S. A.; LOUREIRO, C. F. B. Educação ambiental crítica e interdisciplinaridade: a contribuição da dialética materialista na determinação conceitual. Terceiro Incluído, Goiânia, v. 3, n. 1, p. 1-22, jan./jun. 2013. https://doi.org/10.5216/teri.v3i1.27316

FEITOSA, R. A.; FIGUEIREDO, J. B. D. A. Formação de educadores ambientais na tessitura de um grupo de pesquisa. Pesquisa em Educação Ambiental, v. 8, n. 1, p. 99-113, jan./jun. 2013. https://doi.org/10.18675/2 177-580X.vol8.n1.p99-113

GUIMARÃES, M. Educação ambiental crítica. In: LAYRARGUES, P. P. (Coord.). Identidades da educação ambiental brasileira. Brasília, DF: Ministério do Meio Ambiente, 2004. p. 25-34.

Armadilha paradigmática na educação ambiental. In: LOUREIRO, C. F. B.; LAYRARGuES, P. P.; CASTRO, R. S. (Orgs.). Pensamento complexo, dialética e educação ambiental. São Paulo, SP: Cortez, 2006. p. 15-29.

LAYRARGUES, P. P.; LIMA, G. F. C. Mapeando as macrotendências político pedagógicas da educação ambiental contemporânea no Brasil. In: ENCONTRO "PESQUISA EM EDUCAÇÃO AMBIENTAL” A PESQUISA EM EDUCAÇÃO AMBIENTAL E A PÓSGRADUAÇÃO NO BRASIL, 6. 2011, Ribeirão Preto. Anais... Ribeirão Preto, SP: Universidade de São Paulo, 2011. p. 1-15. Disponível em: <http://www.icmbio.gov.br/educacaoambiental/images/stories/biblioteca/educacao_ambiental/Layrargues_e_Lima_-_Mapeando_ as_macrotend\%C3\%83\%C2\%AAncias_da_EA.pdf>.Acesso em: 20 set. 2018.

LEROY, J.; PACHECO, T. Dilemas de uma educação em tempo de crise. In: LOUREIRO, C. F. B. et al. (Orgs.). Pensamento complexo, dialética e educação ambiental. São Paulo, SP: Cortez, 2006. p. 30-71.

LOUREIRO, C. F. B. Problematizando conceitos: contribuição à práxis em educação ambiental. In: LOUREIRO, C. F. B.; LAYRARGUES, P. P.; CASTRO, R. S. (Orgs.). Pensamento complexo, dialética e educação ambiental. São Paulo, SP: Cortez, 2006. p. 104-61. 
PIMENTA, S. G.; ANASTASIOU, L. G. C. Docência no ensino superior. 4. ed. São Paulo, SP: Cortez, 2010.

TAVARES, G. S. A Formação dos formadores: algumas reflexões sobre teoria e prática pelo viés da educação ambiental. In: RODRIGUES, D. A. M.; VASCONCELOS, F. H. L.; FEITOSA, R. A. (Orgs.). Ensino de ciências e educação profissional: convergências formativas. São Paulo, SP: Pontes, 2017. p. 71-83.

TEIXEIRA, C.; TORALES, M. A. A questão ambiental e a formação de professores para a educação básica: um olhar sobre as licenciaturas. Educar em Revista, Curitiba, v. 30, n. esp. 3, p. 127-44, 2014. https://doi.org/10.1590/0104-4060.38111

TORALES, M. A. A inserção da educação ambiental nos currículos escolares e o papel dos professores: da ação escolar a ação educativo-comunitária como compromisso político-ideológico. Revista Eletrônica Mestrado Educação Ambiental, Rio Grande, v. esp., p. 1-17, mar. 2013. https://doi.org/10.14295/remea.voio.3437

TOZONI-REIS, M. F. C. Formação dos educadores ambientais e paradigmas em transição. Ciência E̊ Educação, Bauru, v. 8, n. 1, p. 83-96, 2002. https://doi.org/10.1590/ S1516-73132002000100007

TRINDADE, D. F. Interdisciplinaridade: um novo olhar sobre as ciências. In: FAZENDA, I. (Org.). O que é interdisciplinaridade? São Paulo, SP: Cortez, 2008. p. 65-84.

Submissão em: $22 / 05 / 2019$

Aceito em: 24/03/2020 